\title{
The Impact of Lecturer-Student Relationship on Self-Esteem and Academic Performance at Higher Education
}

\author{
Sylvester Dodzi Nyadanu (Corresponding author) \\ ECHO Research Group International, P. O. Box 424, Aflao, Ghana \\ E-mail: kdonsyl@gmail.com/ echoresearchgroup.int@gmail.com
}

Tel: 233-209-164-894

Mirrielle Yayra Garglo

Winneba Municipal Hospital, Winneba,

E-mail: garglomiya@yahoo.com Tel: 233-240-300-891

Timothy Adampah

ECHO Research Group International, P. O. Box 424, Aflao, Ghana

E-mail: adampahtim@yahoo.com Tel: 233-205-235-351

\section{Rachel Libline Garglo}

Akatsi South District Health Directorate, Psychiatry unit

E-mail: ralidag@yahoo.com Tel: 233-243-088-316

Received: November 7, 2014 Accepted: December 12, 2014 Published: December 13, 2014

doi:10.5296/jsss.v2i1.6772 URL: http://dx.doi.org/10.5296/jsss.v2i1.6772 


\section{Abstract}

This research examined the effects of lecturer-student relationship on the self-esteem and academic performance of nursing students at the University of Cape Coast, Ghana. The descriptive statistics on the level-clustered random samples indicated two of the lecturer-student relationships, more connectedness and non-threatening, to be positive while the other two, independent and conflicting, were negative relationships. Thus the student-lecturer relationship was an average. With the exception of connectedness, where low score showing less connectedness rather resulted in high self-esteem, the rest of the reported lecturer-student relationships correlated in good dimensions with high self-esteem of the students. However, while the association seemed to promote self-esteem, it rather indicated opposite dimension with regard to academic performance with increasing number of years spent in the department. The study revealed that because there was little interaction between lecturers and students resulting in the average relationship, the prevailing relationship did not directly or not strong enough to influence high academic and high level attainment but rather encouraged high self-esteem which in turn stimulated high academic and level attainment significantly $(p<0.01)$. Hence even-though it is a positive relationship which provides good environment for high academic performance, the reverse is possible especially at the higher education where the long exposure to the socio-cultural practices and the modes of instruction might have had tremendous impact on how students perceive and relate to lecturers in order to enhance their academic performance. We recommend improving student-lecturer relationship to drive self-esteems of students for higher academic performance. It is also suggested that further researches be carried out for modeling, possibly mixed-effects model of the academic performance of students taking into consideration self-esteem, lecturer relationship, socio-cultural and economic factors and other key determinants.

Keywords: Self-esteem, Lecturer-student relationship, Academic performance, Present class, Level
Abbreviations
AS: Anxiety Score
CS: Connectedness Score
I/DS: Independent/Dependent Score
P/CS: Peaceful/ Conflicting Score 


\section{Introduction}

\subsection{Background}

Self-esteem has been used in psychology to reflect a person's overall emotional evaluation of his or her own worth. It is a judgment of oneself as well as an attitude toward the self. Self-esteem encompasses beliefs and emotions such as triumph, despair, pride and shame (Hewitt, 2009). Smith and Mackie (2007) defined self-esteem as the positive or negative evaluations of the self, as in how we feel about it. Alpay (2004) indicated that whilst academic success raises or maintains self-esteem, it is self-esteem which influences performance. That is to say that self-esteem develops out of a person's experiences with success and failure.

Among the most influential factor that an individual relates with, parents and teachers or lecturers are pivotal and very important in developing the mental picture of one's self (Piantaet al., 2003). Based on theories of interpersonal relationships, it is postulated that teachers have a basic need for relatedness with the students in their class which can play a significant role in students' self-concept and expectations regarding scholastic achievements and how to make meaningful life after school (Ewnetu \& Fisseha, 2008). Hence a child's self- esteem is the overall sense of support the child feels from the important people around, particularly parents and teachers (Tam \& Fatimah, 2009). There is a gap between one's ideal self and what he/she perceives to be his or her real self. When the discrepancy is large, the person sees himself as failing to live up to his own goals or values; hence lowering self-esteem.

Self-esteem is developed at an early age through the influences of the parents or guardians and lecturers in particular at higher education. Relationship behaviour of instructors and parents greatly influences self-esteem and academic performance (Santrock, 2007). Because instructor-student relationships are essential to one's social and emotional development, they have the potential influence on how a student succeed in school.

Many researches are on-going but not much is being done in Ghana and particularly at the higher educational levels to assess lecturer-student relationship and its impact on self-esteem and academic performance of students. There is therefore the dearth of information and knowledge about how the relationship between lecturers and students are impacting on academic success, self-esteem and eventually professional performance after school. Hence this study aims at investigating the effect of lecturer-student relationship on self-esteem and academic performance of student at the university level.

\subsection{Problem Statement}

The general public upholds the view that parenting and education are very instrumental in building up an individual. At present, education theories argue that lecturer-student relationships, both social and emotional, play a meaningful role in schooling and learning gains (Creasey et al., 2009). Therefore the role of lecturers in the development of self-esteem and academic works of students needs rigorous research especially in professional trainings such as nursing where nurses are trained to handle human life. The structure, student-to-teacher ratios and the nature of teaching in Ghana do not promote building of good instructor-learner relationship. Additionally, due to the enormous diversity of socio-cultural 
practices and educational structures, researches must be done within the local context to practically assess the impact of the instructor-learner relationship. There is paucity of information and knowledge on this in Ghana since there are extremely limited related researches in Ghana to assess lecturer-student relationship and its effect on self-esteem and academic performance of students particularly at the higher educational level which is the final stage of developing the labour force. Presently, there is a national cry on the high rate of falling in the academic performance of students and their general contribution and competency at work places. Hence the need to unearth the factors contributing to the fall in the education and general performance at work places. Among the indicators, the school environment of which teachers are major component is of key concern. The review of related literatures indicated that even-though more works were done in this field, they were focused mainly on the beginning, lower and middle levels of educational training, neglecting the higher education, especially key professional trainings. Inasmuch as the foundation is very crucial, the final stage of the human resource development also needs attention to solidify the good foundation. Hence this research was intended to bring to a perspective how the lecturer-student relationship at the higher education effects self-esteem and academic performance of the students which may directly or indirectly influence the professional outputs of an individual after schooling.

\subsection{Research Objective and Questions}

The main objective of this study was to investigate and describe the lecturer relationship behaviour as perceived by nursing students and to determine its influence on student's self-esteem and academic performance. Hence the study aimed to answer the following questions;

a) What types of lecturer-student relationships exist in the Department of Nursing of the University of Cape Coast?

b) Does the existing lecturer-student relationship affects students' self-esteem significantly?

c) To what extent does the lecturer-student relationship affects students' academic performance?

d) What are the variations of lecturer-student relationships and self-esteem with year groups?

e) What is the level of correlation between self-esteem and academic performance of the students?

\section{Review of Related Literatures}

Many factors have been found to influence the self-esteem of students which are the environments under which the student is nurtured. These include the school, family and peers (Saunders-Ferguson et al., 2005), social environment and the emerging technologies. Teachers are very important in shaping the self-esteem of students and this is achieved through the kind of relationships that the instructors demonstrate towards students. Self-esteem can be adjusted at any stage in life and can be positive or negative. It is therefore extremely important to emphasize positive developmental change and strive to prevent the negative (Alpay, 2004). 
The type of relationship between the teacher and the student serves as a connection between the two, providing a better atmosphere for a classroom environment (Jones et al., 1981). In a series of descriptive studies, Pianta and Steinberg (1992) and Pianta (1994) showed dimensions of closeness, conflict, and dependency instructor relationship behaviours as perceived and reported by the students to characterise instructor-student relationship. Students who reported more positive involvement with their teachers were found to score high on closeness (secure relationship) sub scale items. The moderately positively involved groups were found on the other hand to be at mid-range on both positive effect (closeness and secure) and negative effect (conflict and dependency) subscale items (Pianta, 1994).

The main factors that influence an individual's self-esteem and academic performance include school environment, teachers, peers, and the curriculum, as well as demographic factors such as parents' background (Gatabu, 2013). Of these, teacher-student relationship is fundamental to the healthy development of students in schools (Myers \& Pianta, 2008), especially to the students' self-esteem. According to Wubbels and Levy (1993), students reported that the best teacher is a strong leader, friendly, understanding, considerate, less uncertain, less dissatisfied, and less admonishing than other teachers on the average. The type of relationship between the teacher and the student can greatly influence the student's behaviour, academic performance and overall sense of social acceptance in the school (Stipek \& Miles, 2008). Teacher relationship quality is especially useful to children with behaviour difficulties or learning problems (Baker, 2006). A close relationship of these children with their teachers showed significant improvement in their scholastic achievements compared to similar classmates without such relationships. Students who had positive teacher relationships demonstrated positive adaptation to school, irrespective of their gender or grade level, across the elementary age range (Baker, 2006). This implied that a student's relationship with teachers has important positive and long-lasting implications for the student's academic and social development. Buyse et al. (2009) indicated that children who experienced conflict teacher-student relationships in the first grade demonstrated lower achievement in mathematics over the following two years. Many other studies showed that students with caring and supportive interpersonal relationships in school reported more positive academic attitudes and values, and more satisfaction in school and are academically balanced (Connell \& Wellbom, 1991; Skinner \& Belmont, 1993; Solomon et al., 2000; Marks, 2000; Ryan \& Patrick, 2001; Voelkl, 1995). In a research to correlate higher levels of teacher-student relationship with improved performance, the relationship had been found to correlate with the student achievement and behaviour in school, regardless of socioeconomic status (Cornel \& Wellbom, 1991; Voelk1, 1995). This was further strengthen in Hughes and Kwok (2007), who found out that students demonstrated higher achievement when there was a higher level of supportive relationships with teachers. This means that in a learning environment where students have good relationship with their teachers, students are more likely to earn higher grades (Willingham et al., 2002, Grobe \& Bishop, 2001). Likewise, Haycock (1998) revealed that the difference between good and bad instructor relationship behaviour is measured in terms of learning achievement to a great deal. Positive or secure relationships of students with instructors may even help the behaviourally at-risk students learn more adaptive behaviour in which supportive instructor-student relationships were associated with declined 
in aggressive behaviour between second and third grade pupils (Meehan et al., 2003). Thus a positive relationship was associated with better achievement and a negative relationship was related to a downward trend in achievement (Ewnetu \& Fisseha, 2008).

Parenting style experienced by students may also influence how they relate with their teachers. Students who perceived their relationships to a teacher negatively were found to experience either authoritarian (controlling and commanding) or permissive and neglecting parenting styles. Their academic achievements were also found to be significantly lower than that of the students with positive relationship behaviour with their teachers and parents (Ewnetu \& Fisseha, 2008). Because great amount of time and working hours were spent by students at school, the time investment indicated the important impact of learning environment on their learning (Larson, 2010) of which the teachers are the key influencers in this learning environment.

DuBois et al. (2002) revealed that environment has been shown to play important role in determining trajectories of adolescents' self-esteem. The type and quality of teacher- student relationships and academic achievement have both been directly linked to high self-esteem attainment (Hamilton \& Howes, 1992). Higher level of association perceived between teachers and students also yielded a higher level of school satisfaction and belongingness (DeSantis et al., 2006) which affected students' self-esteem, studies and performance. This was because the recognition of self-worth of learners or the lack of it can yield an observable trait in the learners which would inspire them either to achieve or not to achieve an aspiration in life (Gatabu, 2013). Pianta (1999) argued that a supportive relationship between instructors and their students fostered more emotionally healthy and academically oriented students and, if established, maintained and supported, shaped a student's development throughout the early school years and beyond. Habibollah et al. (2009) examined self-esteem, gender and academic achievement of undergraduate students using the Persian version of the Rosenberg Self-Esteem Scale (RSES). The findings from this study indicated that self-esteem had a strong significant relationship on academic achievement when gender was controlled (Chi-Square $=14.173$, Sig=.007, $\mathrm{P}<0.01$ ), and there was a relationship between self-esteem and academic achievement (Sig=.074, P >0.05). In a related study, Maruyama et al. (1981) investigation found that high self-esteem facilitates academic achievement but with a limited correlation. Pullmann and Allik (2008) attempted to investigate the direct relationship between self-esteem and academic achievement and found that low general self-esteem did not necessarily point to a poor academic achievement. Their result indicated that low general self-esteem is a significant predictor of superior school performance. However, research finding from Marsh and O'Mara (2008) suggested that prior self-esteem has small positive effect on subsequent educational attainment.

\section{Research Methods}

\subsection{Setting and Study Population}

The Department of Nursing of the School of Biological Sciences, University of Cape Coast, Ghana was established during 2005/2006 academic year. As at 2013, the Department has ten (10) full-time lecturers and nine (9) part-time lecturers. The student population then was 427 (59 at level 100, 43 at level 200, 180 at level 300 and 145 at level 400), giving lecturerto-student ratio as one is to twenty two (1: 22). The study included level 200 to 400 (second 
to fourth year) students because level 100 (first year) students have no or very little interaction with lecturers in the department. Actually at level 100, courses were mostly taken from a number of other departments of the University and hence there was no or little contact with the lecturers from the Department of Nursing.

\subsection{Sampling Techniques}

A quantitative research was conducted using descriptive cross-sectional design to investigate the influence of the lecturer relationship behaviours on self-esteem and academic performance of students of the Nursing Department. A stratified and quota sampling technique was used to sample 120 students from the department. Students were put into strata of levels (year groups) and each level was then given a quota of $33 \%$ to ensure a proportionate representation for each level. The researchers then used convenient sampling to select the 120 respondents

\subsection{Data Collection}

\subsection{Measuring Instruments}

Two psychological and sociological measuring tools were used: Rosenberg's Self-Esteem Scale (SES) and Student Instructor-Relationship Scale (SIRS).

Rosenberg Self-Esteem Scale (SES): The scale is 10 item likert scales with items answered on a 4 point scale - from strongly agree to strongly disagree. For this study, respondents are assessed on their general feelings about themselves using the Rosenberg's SES by circling the appropriate respond. The scores for the 10 items were summed up. The scale ranges from 0-30, with 30 indicating the highest score possible. Higher scores implied higher self-esteem and vice versa. Scores below 15 suggest low self-esteem. This scale generally has high reliability: test-retest correlations are typically in the range of 0.82 to 0.88 , and Cronbach's alpha of 0.72 to 0.87 .

Student Instructor-Relationship Scale (SIRS): The Student-Instructor Relationship Scale was adapted into a 28-item instrument in which respondents considered different relationship qualities with instructors on a 7-point, likert scale. This self-assessment tool was used to measure the perceived lecturer relationship behaviours by students across the four measures: Connectedness, Anxiety, Dependency and Peaceful/Conflicting. Each item was rated and scored. The sum of the scores produced a total score for each category and provided a dimensional measure showing the degree to which lecturers related to students as perceived and reported by the students (Creasey et al., 2009).

\subsection{Data Collection Procedure}

Various prototype questionnaires and guidelines for similar surveys were used and consulted for designing three-part questionnaires.

Part I: collection of data on the socio-demographic and academic performance of the respondents

Part II: Rosenberg self-esteem scale (SES), containing items to elicit information from the respondents

Part III: Adapted Student Instructor-Relationship Scale (SIRS) to gather information from the respondents on their perceived relationship behaviours with lecturers. 
The names of the lecturers in the department were printed separately on pieces of papers and folded. The names were duplicated to almost equal number of students involved in the study and each student was allowed to pick only one piece of paper. This method enabled each student to evaluate a particular lecturer but prevented the student from self-selecting a particular lecturer of his/her own choice to be evaluated. Neither the student nor a lecturer's name was indicated on the questionnaire but each student evaluated only one lecturer. Students were given enough time to respond to the items on the three-part questionnaires to gather data on the socio-demographic and academic performance of the students, their self-esteem and student-lecturer relationships.

The results were entered into Microsoft office and Statistical Package for Social Sciences (SPSS) software for analysis.

\subsection{Ethical Consideration}

Ethical approval was obtained from the research committee of the institution. An informed verbal and written consent was sought from all respondents, explaining to them the nature of the research and how it is prepared to prevent personal identification. Respondents were made to understand that their responses to the questionnaire will remain completely confidential and that the observations were intended to be used only for scientific research purposes solely. To maintain this confidentiality and anonymity, no personal identifier was used or indicated on any document or questionnaire.

\section{Results and Discussion}

A good number of extensive works done by Ewnetu and Fisseha (2008) and Creasey et al. (2009) grouped lecturer relationship behaviours into four cluster relationship behaviours viz Connectedness, Anxiety, Independent/Dependent and Peaceful/ Conflicting. The delimiting score for defining high score was equal or above the cut-off point (cut-off point was set as a score just above the mid of the total score for each scale) and this determined the dimension of the relationship. On connectedness, higher scores denote more connectedness or closeness while high score in Anxiety indicated more anxiety or uneasiness. The Independent/Dependent high score was dimension of independent and vice versa but high score on Peaceful/ Conflicting was a measure of conflicting and vice versa.

Based on the frequency analysis presented in table 1, majority of the respondents, $80.0 \%$ scored higher in connectedness (with the mean $=33.78$; standard deviation $=7.303$ ). This implied that majority of the respondents $(80 \%)$ were well connected with the lecturers as in statements such as "It's not difficult for me to feel connected to this instructor". Regarding a generalized anxiety of students' relationship with the instructors, it was only $35.8 \%$ of the respondents that felt unease with the lecturers with the comparatively the greatest standard deviation of 9.146 indicating the best spread of the anxiety relationship. The degree of dependency/independency scored $71.7 \%$ showing stronger feeling of independent relationship with lecturers. The Peaceful/ Conflicting relationship measurement puts $65.8 \%$ of the respondents to have more conflicting relationship with their lecturers. 
Table 1. Pattern of the lecturer-student relationship perceived by respondents

\begin{tabular}{llllllc}
\hline Lecturer-student relationship type & Cut-off point & $\%(\mathrm{n})$ & Mean & Median & Mode & St. Dev \\
\hline Connectedness score & $28^{+}$ & $80.0(96)$ & 33.78 & 35 & 42 & 7.303 \\
$($ Max 54) & & & & & & \\
Anxiety score (Max 49) & $26^{+}$ & $35.8(43)$ & 22.42 & 22.5 & 13 & 9.146 \\
$\begin{array}{l}\text { Independent/Dependent score } \\
\text { (Max42) }\end{array}$ & $22^{+}$ & $71.7(86)$ & 23.65 & 24 & 25 & 5.18 \\
Peaceful/ Conflicting score (Max 49) & $26^{+}$ & $65.8(79)$ & 24.98 & 24 & 27 & 9.106 \\
\hline
\end{tabular}

This means that only two of the lecturer-student relationships were perceived by respondents in positive direction or as good relationship (that is connectedness and less or non-threatening relationship). Other two relationships were negative relationship whereby $71.7 \%$ of the respondents do not think their lecturers could be depended upon to assist them when they are in a problem as in statements such as "If I were to get into trouble in this class, I do not think this instructor would be very motivated to help me".

All the existing lecturer-student relationships had negative correlation with the self-esteem of students, indicating that the higher the scores on the lecturer-student relationship scale, the lower the self-esteem. This correlation means that high self-esteem individuals scored low on the student-lecturer relationship. The low scores in the student-lecturer relationship were indications in the dimensions of less connectedness, less anxiety perceptions, more dependent (low independent) and more peaceful relationships (low conflicting). Therefore with the exception of connectedness, where low score showing less connectedness rather resulted in high self-esteem, the rest correlated in a good dimension because the low scores indicating low anxiety or unease perception, more dependent and more peaceful relationships produced students with high self-esteem even though the correlations were not statistically significant ( $>0.05$, Table 2). This finding supported the propositions that good relationship between learners and the instructors provide a perfect atmosphere for the learner, promoting social acceptance and belonging and in turn inspire the learner to esteem high in life (DeSantis et al., 2006, DuBois et al., 2002; Hamilton \& Howes, 1992; Gatabu, 2013). This clearly revealed that environment play an important role in developing high self-esteem. The deviation of the connectedness might be due to extremely high expectation or demand by lecturers on students that were very close to them. If the expectation seemed to be beyond the achievable limit of the student, there is a possibility that the student might be thinking he/ she is failing in life which could result in the low self-esteem. 
Table 2. Pearson Correlation of lecturer - student relations behaviour with self-esteem, level and academic performance (present class) of respondents

\begin{tabular}{lllllll}
\hline & \multicolumn{2}{l}{ Self-esteem } & \multicolumn{2}{c}{ Level } & & \multicolumn{2}{c}{ Academic performance } \\
& r-value & p-value & r-value & p-value & r-value & p-value \\
\hline Self-esteem & - & - & $* 0.259$ & 0.004 & $* 0.327$ & 0.000 \\
Connectedness score & -0.134 & 0.146 & -0.052 & 0.572 & -0.093 & 0.315 \\
Anxiety score & -0.023 & 0.802 & 0.188 & 0.040 & 0.114 & 0.214 \\
Independent/ Dependent & -0.143 & 0.120 & -0.135 & 0.141 & 0.146 & 0.113 \\
Peaceful/ Conflicting & -0.138 & 0.133 & 0.103 & 0.262 & 0.111 & 0.229 \\
Present class & $* 0.327$ & 0.000 & 0.134 & 0.145 & - & - \\
\hline
\end{tabular}

Correlation is significant at the 0.05 level (2-tailed),

* Correlation is significant at the 0.01 level (2-tailed).

The academic performance of respondents was measured by the present class designation of the respondents according to the cumulative average grade point per the university's standard. Respondents with $2^{\text {nd }}$ class lower were most connected with the lecturers. Low academic performing respondents, $3^{\text {rd }}$ class students reported the least threatening, most dependent and most peaceful relationship with lecturers followed by $2^{\text {nd }}$ class lower students (Figure 1). Table 2 further established that high academic achieving students tend to report bad lecturer-student relationship of less connectedness, more independent, more unease and conflicting relationship with lecturers. Although none of these correlations was statistically significant $(p>0.05)$ the result showed that negative lecturer relationships were rather related with high academic performance of students. This was not in line with other findings, most of which were focused at the beginning to middle level of education, that suggested that good or positive student-teacher relationship promotes high academic achievement while a negative relationship related to a downward trend in academic achievement (Ewnetu \& Fisseha, 2008; Pianta, 1999; Willingham et al., 2002, Grobe \& Bishop, 2001; Haycock, 1998; Hughes \& Kwok, 2007). This means that even-though positive relationship promotes academic performance, this might not be the case always especially at the higher educational level where socio-cultural practices, existing educational policies and mode of lecturing especially within the context and content of Ghanaian university education might have had tremendous impact on how students perceived and relate with lecturers in order to enhance their academic performance. Because there was extremely little interaction between lecturers and students, students related weakly with the lecturers as showed by the weak correlation coefficient (Table 2) but only took the academic instructions seriously while habouring negative relationships with lecturers or were not happy with the existing relationship. This could also mean that the students could have performed far better than this if their relationship with lecturers should have been improved. This effect could also account for complain by Ghanaian employers of low performance at work by graduates after completion even among high academic achieving individuals, since they were trained under timid conditions. 


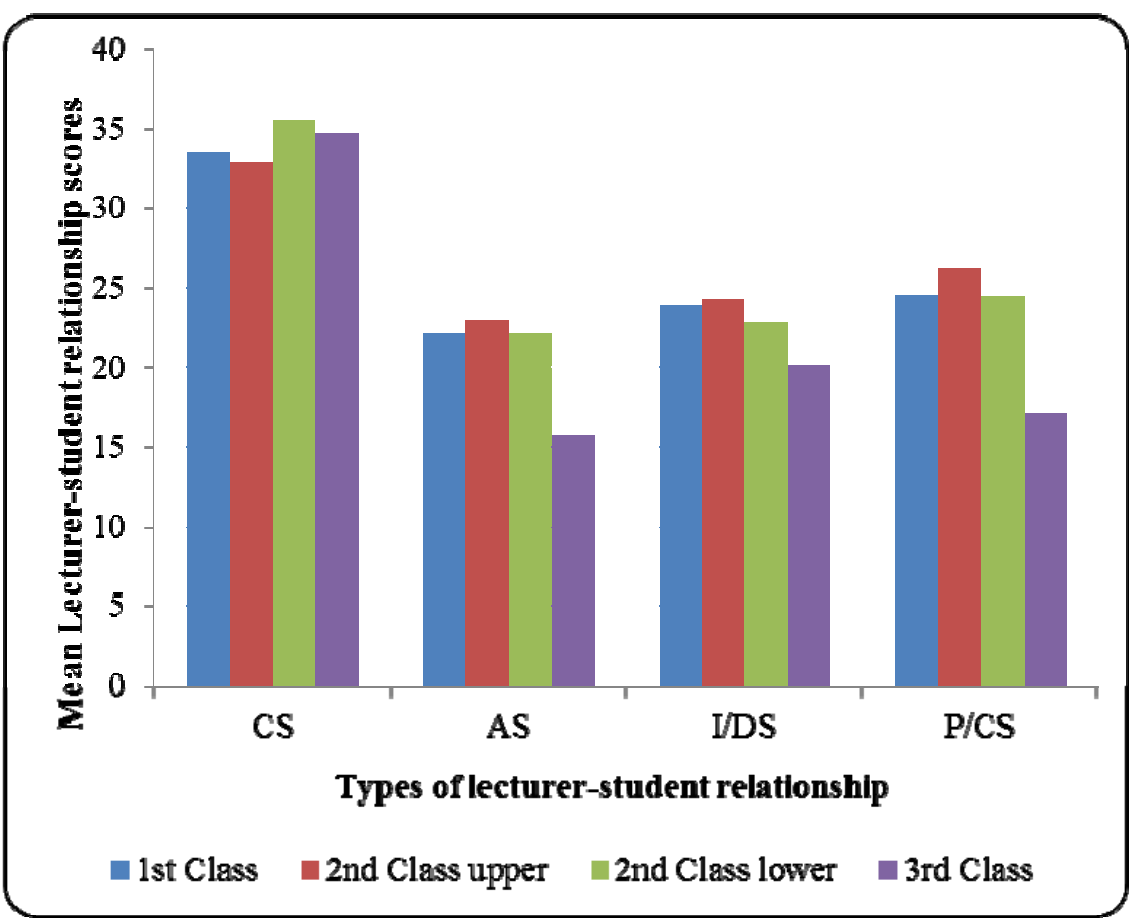

Figure 1. Mean lecturer relationship behaviour reported by respondents of various academic performances

Level 300 students were best connected to the lecturers and with least threatening perceptions of anxiety affiliation. The level 300 students also had the strongest feelings of independency but were most peaceful with the lecturers. Level 400 respondents reported least closeness with the lecturers and also had most conflicting relationship perception with lecturers (Figure 2 ). Generally, the same negative correlation continued as students progressed in their academic years (Table 2). However, there were no significant relationships between all the perceived relationships and the levels $(\mathrm{p}>0.05)$, except anxiety which showed significance $(\mathrm{p}<0.05)$. 


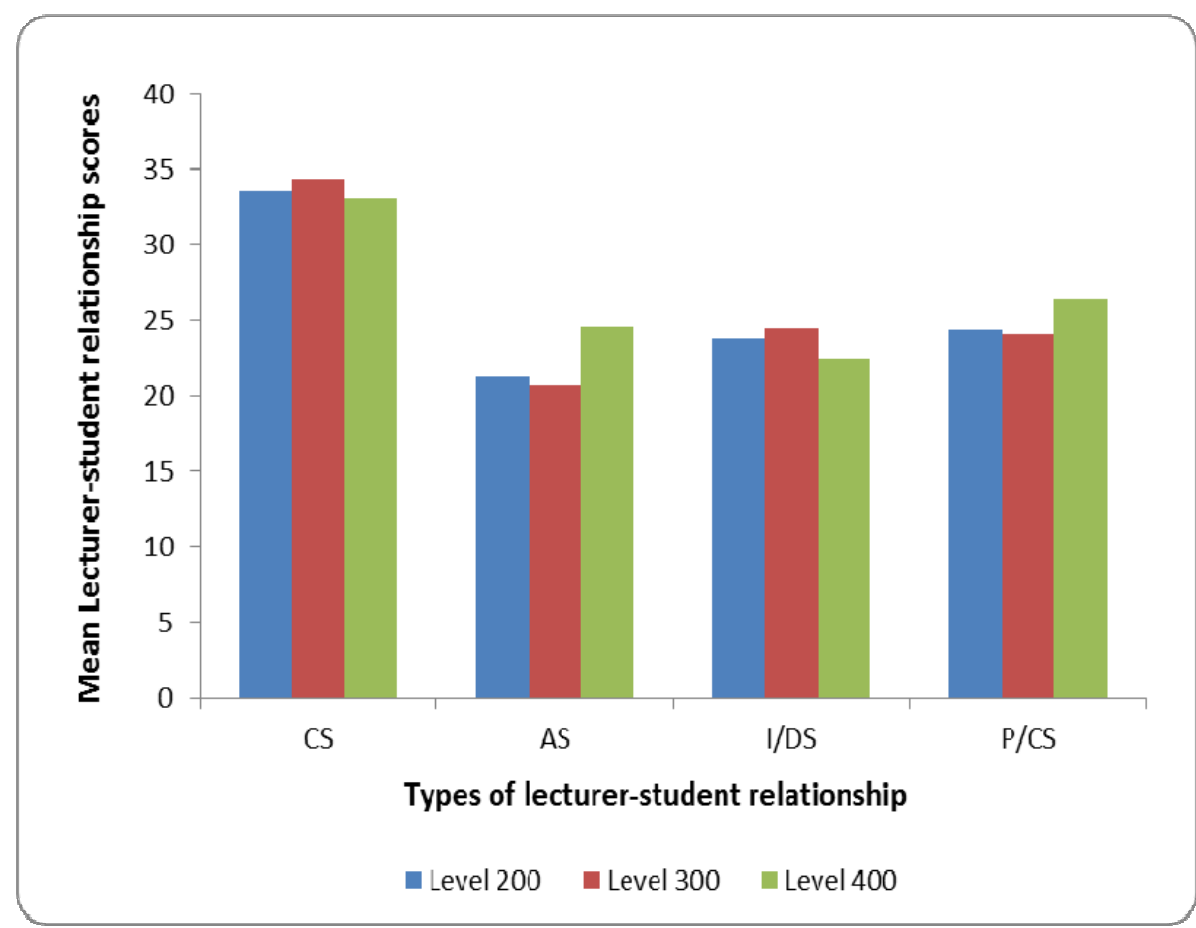

Figure 2. Lecturer relationship behaviour perceived by respondents at various academic levels

Respondents at higher levels reported less closeness or connectedness with their lecturers $(\mathrm{r}=$ -0.052, $\mathrm{p}=0.572$ ). With regard to anxiety, the higher-level respondents had generalized anxiety relationship with the lecturers significantly $(\mathrm{r}=0.188, \mathrm{p}<0.05)$. This means that as students progressed to high levels, they began to keep distance from lecturers and feel unease relating freely with lecturers. The result also indicated that the higher the students advanced in levels the more but weak dependent relationship they built with the lecturers $(r=0.135, p$ $=0.141$ ) with level 300 respondents most dependent but not significant (Table 2, Figure 2). Besides the lecturers' limited interaction with students, other external factors might have contributed to the negative student-lecturer relationship directly and/or indirectly which are beyond the scope of this research.

From the analysis, the self-esteem rose sharply from level 200 to 300 and then continued to rise gently to level 400 (Figure 3). Respondents of higher levels have higher self-esteemed than those of lower levels and was found to be statistically significant $(r=0.259, \mathrm{p}<0.05$, Table 2). This might be possible because as one gets closer to finishing higher education, there is a high development of the mental picture of one's self (Pianta et al., 2003) as the individual begins to aspire higher in life's achievement, assuming more socially accepted and becoming better position to contribute to socio-economic development and self-contentment. 


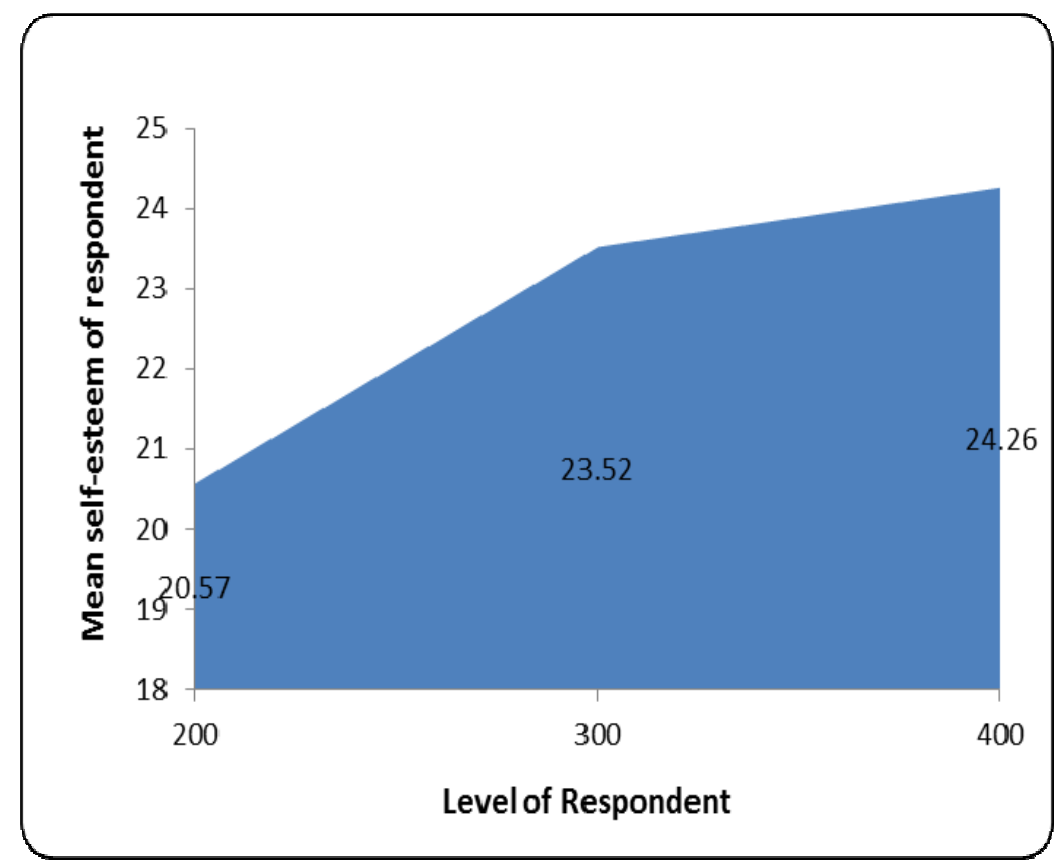

Figure 3. Variation of self-esteem with academic levels (year groups) of respondents

The self-esteem of the respondents increased with academic performance (Figure 4) and was found to have significant positive relationship on academic achievement $(r=0.327, p<0.01$, Table 2) in line with other findings (Ewnetu \& Fisseha, 2008; Habibollah et al., 2009). This means that student's self-esteem drives him/her to aspire high in life and thereby gets motivated to attain better class or perform very creditably academically. The self-concept is therefore very instrumental in the achievement of one's desires in life even-though it was found to be of weak correlation (Maruyama et al., 1981). Additionally, the weak positive correlation was an indication that the academic performance of students did not necessarily point to a high self-esteem as found by Pullmann and Allik (2008). Hence academic performance of the students seemed to be multi-factorial of which key indicators might include self-esteem, student-lecturer relationship, general learning environment and socio-cultural backgrounds. Self-esteem of the respondents is also affected by other factors such as parenting styles, peer and duration of exposure in life starting from infancy (Santrock, 2007). 


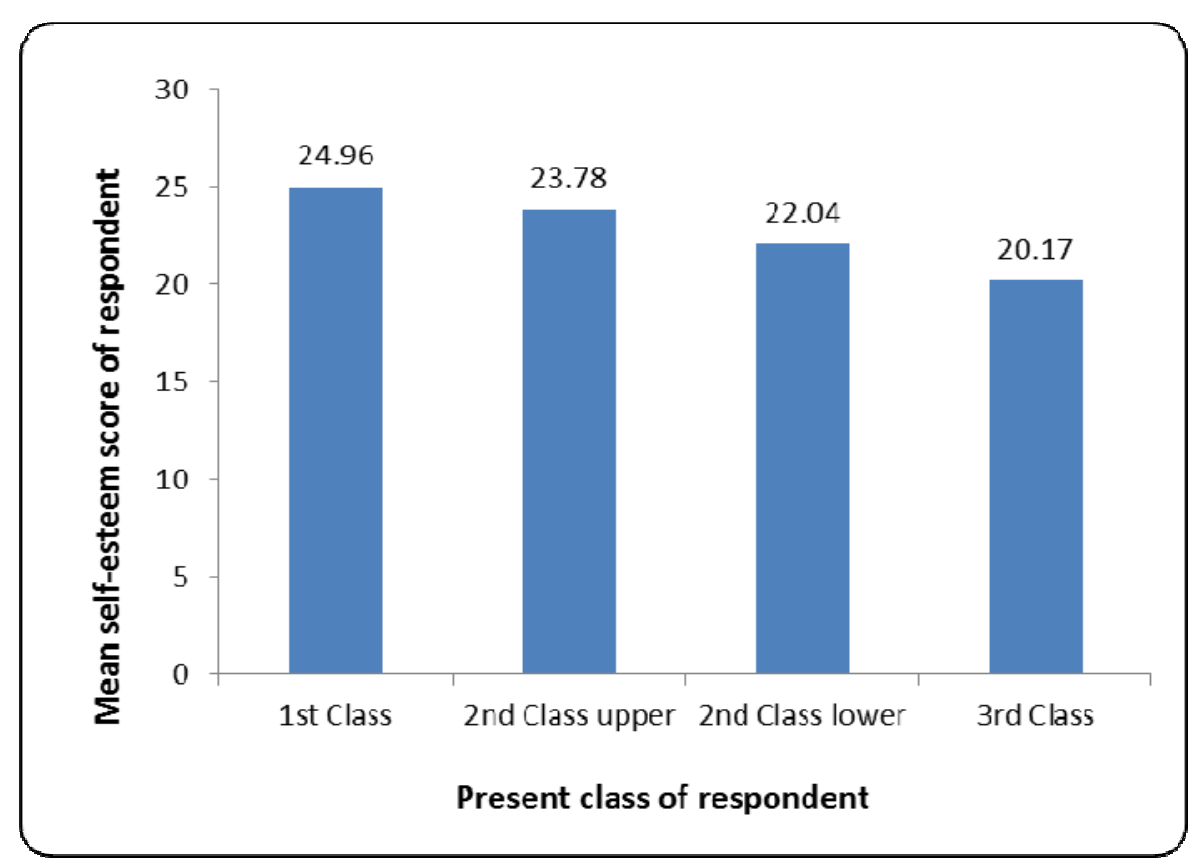

Figure 4. The effect of self-esteem on academic performance of respondents

\section{Conclusion}

The study generally revealed that only two of the lecturer-student relationships were perceived by the respondents to be in positive direction or as good relationship (80\% connectedness and $64.2 \%$ less threatening relationships) but $68.8 \%$ conflicting and independent of $71.7 \%$ relationships were rather bad or negative relationships. Although statistically not significant $(p>0.05)$, the study showed that high academic and high level attaining students generally reported having negative relationship with their lecturers such as less connected, more independent and more conflicting relationships. Possibly because the high self-esteem, however, promotes attainment of better class with progress in academic years. Thus high academic and level attaining students appeared not to be comfortable with the nature of the association or had negative relationship with lecturers and therefore distant themselves from the lecturers but take their academic instructions seriously. The findings revealed that at higher education with limited interaction with lecturers, as students built strong self-confident and self-determination they turned to lower their closeness to lecturers and began to develop negative relationships (such as more independent, more conflicting and anxiety) with lecturers. It could also be concluded that lecturers seemed to solely focus on academic instructions and delivery while disregarding the component of establishing relationships with students, hence high academic performance but poor relationship. In addition, the weak correlation indicated that the existing student-lecturer relationship did not have strong direct effect on self-esteem and academic performance.

Hence even-though positive relationship was found in other studies mostly at lower and middle educational level to promote academic performance, this study at a higher education revealed the reverse. This might be possible especially at the higher education at which point the long- term exposures of socio-cultural practices, existing educational policies and mode of lecturing had tremendously influenced how students perceive and relate their association 
with lecturers to high academic performance, resulting in negative relationships. This is likely to have serious long-term negative effects on students after completing higher education such as bad human relation at work which is a general complain of Ghanaians on bad customer or client care and relation. However, it should be stated here that academic performance and self-esteem are influenced by multiple factors which can be modeled with regression.

\section{Recommendations}

Good lecturer-student relationship is indispensable to students' holistic and long-term development. Policy makers, university authorities and students must try their best to build good student-lecturer relationship that improve education. The following recommendations are therefore made based on the major findings of this study:

a) Policy makers in education and lecturers should strive more to devise ways in school system patterns and internal school arrangements for instructors to offer other useful interactions and mentoring students besides just giving academic instructions.

b) This is a department which trains health professionals to handle patients; efforts should therefore be made by the lecturers and the authorities to instil the sense of good relationship in the nursing students for quality healthcare delivery.

c) The research should be done over periods of time to actually assess if the perception students hold of their lecturers change considerably over time.

d) Further research should be done where lecturers also assess how they perceive student-lecturer relationship within the department and necessary findings incorporated with that of the students' perception.

e) Further research should be carried out to find out if academic performance and self-esteem developed during schools actually influence professional outputs of workers

f) It is also suggested that further researches be carried out to develop mixed-effects model of the academic performance of students taking into consideration self-esteem, lecturer relationship, socio-cultural and economic factors and other key determinants.

\section{Acknowledgement}

This research is financed by the researchers. We are very grateful to the nursing department of the University of Cape for their support. We also appreciate the willingness of the respondents in participating in this study.

\section{References}

Alpay, E. (2004). Self-Concept and Self-Esteem. Department of Chemical Engineering and Chemical Technology, Imperial College of Science, Technology and Medicine, Prince Consort Road, London. SW7 2BY.

Baker, J. A. (2006). Contributions of teacher-child relationships to positive school Adjustment during elementary school. Journal of School Psychology, 44(3), 211-229. http://dx.doi.org/10.1016/j.jsp.2006.02.002

Buyse, E., Verschueren, K., Verachtert, P., \& Van Damme, J. (2009). Predicting school adjustment in early elementary school: Impact of teacher-child relationship quality and 
relational classroom climate. Elementary School Journal, 110(2), 119-141. http://dx.doi.org/10.1086/605768

Connell, J. P., \& Wellbom, J. G. (1991). Competence, autonomy, and relatedness: a motivational analysis of self-system processes. In M. R. Gunnar \& L. A. Sroufe, (Eds). Self Processes in Development: Minnesota Symposium on Child Psychology. (Vol. 23, pp. 43-47) Chicago, Ill: University of Chicago Press.

Creasey, G., Jarvis, P., \& Knapcik, E. (2009). A Measure to Assess Student-Instructor Relationships. International Journal for the Scholarship of Teaching and Learning, 3(2).

DeSantis King, A. L., Huebner, S., Suldo, S. M., \& Volois, R. F. (2006). An ecological view of School satisfaction in adolescence: Linkages between social support and behaviour problems. Applied Research in Quality of Life.

DuBois, D. L., Burk-Braxton, C. A., Swenson, L. P., Tevendale, H. D., \& Hardesty, J. L. (2002). Race and gender influences on adjustment in early adolescence: Investigation of an integrative model. Child Development, 73(5), 1573-1592. http://dx.doi.org/10.1111/1467-8624.00491

Ewnetu \& Fisseha. (2008). The Teacher Relationship Behaviour and Parenting Style Correlates of Students' Scholastic Achievement at Grade Seven English. Ethiop. J. Education. \& Science, 4(1).

Gatabu, F. (2013). Self-esteem and academic performance of students in public secondary schools in Ndhiwa district. Kenya.

Grobe, C., \& Bishop, G. (2001). School Attributes and Student Achievement. New Brunswick: Department of Education.

Habibollah, N., Rohani, A., Tengku, A. H., Jamaluddin, S., Kumar, V. (2009). Self-esteem, gender and academic achievement of undergraduate students. American Journal of Scientific Research, pp. 26-37. Retrieved from http://www.eurojournals.com/ajsr.htm

Hamilton \& Howes, C. (1992). Children's Relationship with Care Givers: Mothers and Childcare Teachers. Child Development, 63(4).

Haycock, K. (1998). Good Teaching Matters A lot. The Center for the Future of Teaching \& Learning, Suite 220, Santa Cruz.

Hewitt, J. P. (2009). Oxford Handbook of Positive Psychology. (pp. 217-224). Oxford University Press.

Hughes, J., \& Kwok, O. (2007). Influence of student-teacher and parent-teacher relationships on lower achieving readers' engagement and achievement in the primary grades. Journal of Educational Psychology, 99, 39-51. http://dx.doi.org/10.1037/0022-0663.99.1.39

Jones, V. F., \& Louise, J. (1981). Responsible Classroom Discipline. (pp. 95-215). Boston: Allyn and Bacon, Inc.

Larson, R. (2010). Teacher-Student Relationships and Student Achievement. University of Nebraska at Omaha.

Marks, H. M. (2000). Student engagement in instructional activity: patterns in the elementary, middle, and high school years. Am Educ Res J, 37(1), 153-184. http://dx.doi.org/10.3102/00028312037001153 
Marsh, H. W., \& O’Mara, A. (2008). Reciprocal effects between academic self-concept, self-esteem, achievement, and attainment over seven adolescent years: Unidimensional and multidimensional perspectives of self-concept. Personality and Social Psychology Bulletin, 34, 542-552. http://dx.doi.org/10.1177/0146167207312313

Maruyama, G. M., Rubin, R. A., \& Kingsbury, G. G. (1981). Self-esteem and educational achievement: Independent constructs with a common cause? Journal of Personality and Social Psychology, 40(5), 962-975. http://dx.doi.org/10.1037/0022-3514.40.5.962

Meehan, B. T., Hughes, J. N., \& Cavell, T. A. (2003). Teacher-student relationships as compensatory resources for aggressive children. Child Development, 74, 1145-1157. http://dx.doi.org/10.1111/1467-8624.00598

Myers, S. S., \& Pianta, R. C. (2008). Developmental commentary: Individual and contextual influences on student-teacher relationships and children's early problem behaviours. Journal of Clinical \& Adolescent Psychology, 37, 600-608. http://dx.doi.org/10.1080/15374410802148160

Pianta, R. C, Hamre, B., \& Stuhlman, M. (2003). Relationships between teachers and children. In W. Reynolds \& G. Miller (Eds.), Comprehensive handbook of psychology: Vol. Educational psychology (pp. 199-234). Hoboken, NJ: Wiley \& Sons, Inc.

Pianta, R. C., \& Steinberg, M. (1992). Teacher-Child relationships and the process of adjusting to school. In Pianta (Ed.), Beyond the Parent: The Role of Other Adults In Children's Lives (pp. 61-80). San Francisco: Jossey-Bass.

Pianta, R. C. (1994). Patterns of Relationships between Children and Teachers: Association with classroom and home behavior. Journal of applied developmental psychology, 32(1).

Pianta, R. C. (1999). Enhancing Relationships Between Children and Teachers. Washington, DC: American Psychological Association. http://dx.doi.org/10.1037/10314-000

Pullmann, H., \& Allik, J. (2008). Relations of academic and general self-esteem to school achievement. Personality and Individual Differences, 45(6), 559-564. http://dx.doi.org/10.1016/j.paid.2008.06.017

Ryan, A. M, \& Patrick, H. (2001). The classroom social environment and changes in adolescents' motivation and engagement during middle school. Am Educ Res J., 38(2), 437-460. http://dx.doi.org/10.3102/00028312038002437

Santrock, J. W. (2007). A topical approach to life-span development. (3rd Ed.) New York: McGraw-Hill.

Saunders-Ferguson, R., Barnett, Gerald, C., \& Ten Broeck, S. (2005). Self-Esteem Assessment of Adolescents Involved in Horsemanship Activities. United States of America, Florida.

Skinner, E. A., \& Belmont, M. J. (1993). Motivation in the classroom: reciprocal effects of teacher behaviour and student engagement across the school year. J. Educ Psychol., 5(4), 571-581. http://dx.doi.org/10.1037/0022-0663.85.4.571

Smith, E. R., \& Mackie, D. M. (2007). Social Psychology. p. 107.

Solomon, D., Battistich, V., Watson, M., Schaps, E., \& Lewis, C. (2000). A six district study of educational change: direct and mediated effects of the Child Development Project. Soc Psychol Educ., 4, 3-51. http://dx.doi.org/10.1023/A:1009609606692 
Stipek, D., \& Miles, S. (2008). Effects of aggression on achievement: Does conflict with the teacher make it worse? Child Development, 79, 1721-1735. http://dx.doi.org/10.1111/j.1467-8624.2008.01221.x

Tam, C. L., \& Fatimah, Y. (2009). The Effects of Family Functioning on Self-Esteem of Children. European Journal of Social Sciences, 9(4).

Voelkl, K. E. (1995). School warmth, student participation, and achievement. J. Exp Educ, 63, 127-138. http://dx.doi.org/10.1080/00220973.1995.9943817

Willingham, W. W., Pollack, J. M., \& Lewis, C. (2002). Grades and test scores: accounting for observed differences. J. Educ Meas, 39(1), 1-37. http://dx.doi.org/10.1111/j.1745-3984.2002.tb01133.x

Wubbels, T., \& Levy, J. (1993). Do you know what you look like? Interpersonal relationships in education. London: Falmer.

\section{Copyright Disclaimer}

Copyright reserved by the author(s).

This article is an open-access article distributed under the terms and conditions of the Creative Commons Attribution license (http://creativecommons.org/licenses/by/3.0/). 